Grossbard, E. (1952). J. gen. Microbiol. 6, 295-310.

\title{
Antibiotic Production by Fungi on Organic Manures and in Soil
}

\author{
By ERNA GROSSBARD \\ Imperial College of Science and Technology, London
}

\begin{abstract}
SUMMARY: Penicillium patulum, Aspergillus clavatus and $A$. terreus produced antibiotic substances when grown on organic materials which are used or could be used as manures. The addition of glucose increased the antibiotic titre in every case.

Antibiotics were also formed in autoclaved soils enriched with easily available carbon sources and inoculated with one of the following fungi: P. patulum, A. clavatus, A. terreus and two unidentified species of Penicillium. P. patulum formed an antibiotic also on partially sterilized supplemented soil. The degree of antibiotic activity was decreased when soil cultures of $\boldsymbol{P}$. patulum were contaminated with other organisms from soil or from the air, but even gross contamination with natural soil at $\mathbf{2 5}^{\circ}$ did not destroy activity entirely until 11 days had elapsed. Loss of activity was smaller at lower temperatures.
\end{abstract}

The soil is the natural habitat of the majority of micro-organisms which produce antibiotics when grown on laboratory culture media. Some of these substances inhibit in vitro the germination of fungal spores and the growth of certain fungal plant pathogens. If, therefore, the soil flora could be induced to form antibiotics in the soil it might be possible to control soil-borne pathogens very effectively by inhibiting their development in the soil. However, in culture work, abundant antibiotic production necessitates a high level of nutrition and the use of complex media, and it does not follow that even organisms whose natural habitat is the soil can form significant amounts of antibiotics therein, as it is a nutritionally poor medium (Waksman, 1948). The addition of microbial food would therefore seem necessary for antibiotic production, but nevertheless it is known that substances can be extracted from untreated soil which inhibit the growth of micro-organisms (Winter, 1940; Waksman \& Woodruff, 1942).

Indirect evidence of antibiotic action in the field is provided by the large number of reports which show that certain soil-borne pathogens may be controlled by the use of organic manures, for example farmyard and various green manures, and straw. Many factors, such as competition for food, accumulation of carbon dioxide (Garrett, 1944), and alteration of $\mathrm{pH}$, are known to contribute to the effect, but antibiotic formation by the developing soil microflora might also hinder the development of pathogens.

Evidence of antibiotic production in supplemented soil cultures was secured by Lewis (1929) using bacteria, and by Nickell \& Burkholder (1947) with actinomycetes. Preliminary accounts of work with fungi were given by Grossbard $(1947,1948 a)$, who showed that although extracts from autoclaved soil inoculated with Penicillium patulum failed to inhibit the growth of certain bacteria and fungi, when the soils were supplemented with carbohydrate the 
centrifugates from such soils displayed considerable antibiotic activity. Grossbard $(1948 b, 1949,1950)$ found that two unidentified species of Penicillium, Aspergillus terreus and $A$. clavatus, could also form antibiotics in enriched soil, while Gottlieb \& Siminoff $(1950 a)$ showed that $A$. clavatus was active in this way. Brian, Wright, Stubbs \& Way (1951) secured evidence concerning the formation of griseofulvin in the soil by $\boldsymbol{P}$. griseofulvum. The production of antibacterial substances in unsterilized soil supplemented with microbial food, and their presence in the aqueous phase of the soil, has been demonstrated by Nandi (1948).

The present paper deals with antibiotic production by soil fungi, especially $\boldsymbol{P}$. patulum, cultivated on organic materials which are used or could be used as manures, and in soil to which various carbohydrates were added. Grossbard (1945) showed that $A$. clavatus formed antibiotic material when grown on wheat straw. P.patulum, A. clavatus and $A$.terreus were chosen for the present investigations because they all produce expansine (synonyms : clavacin, clavatin, claviformin, patulin, penicidin, anhydro-3-hydroxymethylenetetrahydro-1 : 4pyrone-2-carboxylic acid) in culture media of defined composition. This antibiotic is formed by a wide range of soil fungi and shows, in addition to antibacterial properties, marked antifungal activity. The ultimate object of this work is to establish whether the formation of antibiotics in natural soil by fungi is possible and whether this can be an important factor in the control of certain root diseases by organic manuring.

\section{MATERIALS AND METHODS}

Organisms. P. patulum Bainier, strain P. 189, supplied by Mr G. Smith, was used. According to Raper \& Thom (1949) $P$. patulum is identical with $P$. urticae Bainier. Two isolates of $A$. clavatus Desm., kindly supplied by Roche Products, Ltd., $A$. terreus Thom, (NCTC 3911) and two unidentified species of Penicillium were also used. The latter were isolated by the author from the rhizosphere of tomato seedlings growing in soil infected with Phytophthora parasitica but which nevertheless remained healthy.

Manures and soils. The plant materials were harvested in July or September and comprised bracken (Pteridium aquilinum Kuhn), red fescue (Festuca rubra L.), Italian rye grass (Lolium multiflorum Lam.), lawn mowings, white mustard (Brassica hirta Moench), red clover (Trifolium pratense L.), lucerne (Medicago sativa L.), sainfoin (Onobrychis viciaefolia Scop.), timothy grass (Phleum pratense L.) and wheat straw. Most of these crop plants were supplied by district officers of the National Agricultural Advisory Service; samples of timothy grass and red fescue were supplied by the Welsh Plant Breeding Station. Other materials tested were well decomposed horse manure from animals bedded on wheat straw, and sugar-beet pulp supplied by the British Sugar Corporation Ltd.

Most of the work was carried out on a medium loam subsoil, of a type frequently used for mushroom bed casings. The author is indebted to Dr O. Owen for the following analysis : total nitrogen, $0.41 \%$; organic carbon 
(Walkley \& Black), $3 \cdot 23 \%$; citric acid soluble potash $\left(\right.$ as $\mathrm{K}_{2} \mathrm{O}$ ), $0 \cdot 029 \%$; citric acid soluble phosphate (as $\mathrm{P}_{2} \mathrm{O}_{5}$ ), $0.015 \%$; carbonates, slight traces; $\mathrm{pH}$ value, $\mathbf{5 . 5 2}$.

Preparation of materials. The manures were sometimes used in the fresh and the decomposed state, fresh materials being cut into short lengths. Quantities (10 g.) were put into 250 or $500 \mathrm{ml}$. Erlenmeyer flasks with $100 \mathrm{ml}$. of distilled water and autoclaved at $15 \mathrm{lb}$./sq.in. for $20 \mathrm{~min}$. In several cases $3.5 \%(w / w)$ of glucose was added before autoclaving.

The soil was passed through a $2 \mathrm{~mm}$. sieve and the water content adjusted to $100 \%$ of the moisture holding capacity, which varied according to the supplement. Portions (100 g.) of soil, alone or supplemented with glucose, sugar-beet pulp or wheat straw, were placed in $250 \mathrm{ml}$. Erlenmeyer flasks and autoclaved at $15 \mathrm{lb}$./sq.in. for $1 \mathrm{hr}$. or placed in an already boiling steamer for $30 \mathrm{~min}$.

Inoculation procedure. The manures were inoculated with a loopful of spores from 1-week slope cultures of the fungi grown on a medium in distilled water and containing (as \%, w/w) $\mathrm{NaNO}_{3}, 0.3 ; \mathrm{KH}_{2} \mathrm{PO}_{4}, 0 \cdot 1 ; \mathrm{KCl}, 0.05 ; \mathrm{MgSO}_{4} .7 \mathrm{H}_{2} \mathrm{O}$, $0.05 ; \mathrm{FeSO}_{4} .7 \mathrm{H}_{2} \mathrm{O}, 0.001$; glucose, 4.0 ; malt extract (Allen and Hanburys Ltd.), $0 \cdot 2$; agar, $\mathbf{1} \cdot 5$.

The soils were inoculated with $10 \mathrm{ml}$. of spore suspension in distilled water prepared from the above slope cultures; $10 \mathrm{ml}$. water/slope were used and further diluted 10 times. Controls were set up in a similar manner, omitting inoculation with the fungus.

Extraction of the cultures. Manures and soils were incubated at $25^{\circ}$ and usually assayed at weekly intervals. The soil cultures were centrifuged for 45 min. at 2800 r.p.m. (r.c.f. 2260). The fluids obtained, as well as samples pipetted from the manure cultures, were assayed without further treatment.

\section{Assay of antibiotic activity}

Antibacterial activity. Bacillus mycoides Flügge and Bacterium carotovorum Jones (both supplied by Dr W. J. Dowson) were chosen as test organisms, the former because of its considerable sensitivity to inhibition or stimulation by soil extracts and its ability to show clearly partial degrees of inhibition. The latter was included not only because it was Gram-negative but because, being a plant pathogen, it appeared suitable for use in investigations bearing on the control of soil-borne plant diseases. Occasionally Bact. coli (NCTC 86) was used.

The cylinder-plate method was used at first and later the cup-plate method, employing a medium made up in distilled water and containing (as $\%$, w/w) Difco beef extract, 0.3; Difco yeast extract, 0.3; Bacto-peptone, 1.0; $\mathrm{NaCl}$, $0 \cdot 5$; agar, $1 \cdot 15 ; \mathrm{pH} 6 \cdot 8$.

Yeast extract was incorporated because the zones of inhibition formed by Bact. carotovorum on this medium were comparatively well defined. The medium was bulk-seeded from $18 \mathrm{hr}$. broth cultures of the test organisms, giving a final 1/200 dilution of the inoculum. Expansine was used as a standard for assessing the activity of the test fluids, and the results have usually been expressed in terms of the 'expansine equivalent', the quantity of antibiotic, 
calculated as expansine, present in a culture. Expansine was dissolved either in $\mathrm{pH} 6.5$ buffer solution or in the centrifugates from the controls in the soil experiments. A standard curve was constructed daily from the readings obtained from a range of concentrations. Each assay plate contained two concentrations of the standard. The unknown was tested in six or ten replicates for each organism. The samples of expansine were given by Boots Pure Drug Co. Ltd. and by Roche Products Ltd.

Antifungal activity. The serial dilution method was used. The medium was pea broth (Leonian, 1934) and the test organisms were the plant pathogens Ph. parasitica Dastur and Thielaviopsis basicola Ferraris (supplied by $\mathbf{M r}$ P. H. Williams) grown on potato glucose agar. Tubes $(6 \times 1$ in.) containing $10 \mathrm{ml}$. of medium including the various concentrations of test fluids were inoculated with $P$. parasitica by means of $5 \mathrm{~mm}$. disks cut from the most recent zone of growth in cultures 7 days old. The inoculum of $T$. basicola was a loopful of spores. The tubes were examined at intervals of 5 days; the results presented are those obtained after 3 weeks at $25^{\circ}$.

\section{RESULTS}

Antibiotic production by Penicillium patulum on various substrates

The first point to be decided was whether organic materials which are used or could be used as manures would support antibiotic production. Using wheat straw and timothy grass, the results shown in Fig. 1 were obtained. Here the 'expansine equivalents' are plotted on a logarithmic scale (base 2) against time. Evidently these materials (at least after being autoclaved) are adequate substrates for antibiotic production by this fungus. In both cases production was rapid, and when the first assays were done at the end of a week, the timothy grass culture contained more than twice as much antibiotic as the straw. Between the second and ninth weeks activity in the straw cultures remained constant, after which a slow decline set in. The decline in the timothy grass culture began sooner and was more rapid and after 23 weeks very little activity could be detected, although the straw cultures still showed a moderate degree of activity.

The results of further experiments with a variety of materials, in which trials were also made with the addition of $3.5 \%$ glucose, are shown in Tables 1 and 2. The previous finding that maximal concentrations of antibiotic were frequently present after about 2 weeks, following which there was usually a decline, was confirmed. Accordingly only the results obtained after 14 days are recorded in Tables 1 and 2, in which the expansine equivalents are related to that present in a wheat straw culture, taken as one hundred.

The results show that antibiotic material was produced on several media, the best being sugar-beet pulp. Some media (Table 1) consistently gave the same type of response, i.e. always some antibiotic activity or always no activity at all, whenever tested. Others (Table 2) gave much more variable responses, in that their adequacy or otherwise seemed to depend on the district in which the crop was grown, as is indicated by the results with red 
clover and rye grass. The time at which the material was harvested may also be important, as is suggested by the data relating to mustard. It is possible that different strains or varieties would have given different results but no evidence to support this hypothesis is available. Generally, the leguminous crop materials were unsuitable, though one of four red clover samples did support the formation of a stable antibiotic. In the others there was some activity at 4 days, which gradually decreased and was seldom detectable after 8-10 days. With unsuitable materials the addition of glucose led to the formation of antibiotic of considerable titre, indicating that the absence of activity was probably due to the lack of a suitable carbon source. The addition of

Table 1. Relative antibacterial activity of 14-day cultures of Penicillium patulum on substrates giving qualitatively constant results, and the effect of the addition of glucose

Relative to wheat straw as 100 , which here represents an expansine equivalent of $50 \mathrm{mg}$. Test organism, B. mycoides.

\begin{tabular}{lrc} 
Substrate & $\begin{array}{r}\text { Alone } \\
\text { Whelative antibacterial activity (\%) }\end{array}$ & $\begin{array}{c}\text { With 3.5 \% } \\
\text { glucose }\end{array}$ \\
\cline { 2 - 3 } Wheat straw, fresh & 100 & 426 \\
Lawn mowings, fresh & 0 & $\mathbf{3 9 1}$ \\
Lawn mowings, composted & $\mathbf{8 0}$ & $\mathbf{4 0 0}$ \\
Bracken & 0 & $\mathbf{3 8 0}$ \\
Timothy grass & $\mathbf{3 3}$ & $\mathbf{2 7 4}$ \\
Sugar-beet pulp & 200 & $\mathbf{4 2 6}$ \\
Lucerne & $\mathbf{3 1 6}$ & - \\
Sainfoin & 0 & $\mathbf{2 0 0}$ \\
Horse manure & 0 & $\mathbf{5 4}$ \\
& 0 & -
\end{tabular}

glucose to materials already adequate always caused a large increase in antibiotic titre. It is interesting to note that suitable materials became unsuitable after composting, but became suitable again when supplemented with glucose. Apparently sources of available carbon were removed during the decomposition.

No correlation was found between rate of growth and sporulation in the cultures, and antibiotic production. Wheat straw cultures showed comparatively slow growth and sporulation but a high antibiotic titre, while lucerne cultures, though inactive, grew rapidly and spored heavily, as also did active cultures of lucerne + glucose. The rates of decrease of antibiotic activity during continued incubation varied with different substrates, confirming the results shown in Fig. 1. Glucose favoured maintenance of activity for prolonged periods.

\section{Antibiotic production by Aspergillus clavatus and A. terreus on various substrates}

The results of tests with $A$. clavatus and $A$. terreus grown on wheat straw, sugarbeet pulp, timothy and fescue grasses, mustard, lucerne and horse manure are shown in Table 3; only the activities after 14 days' incubation are given. The 
Table 2. Relative antibacterial activity of 14-day cultures of Penicillium patulum on substrates which gave qualitatively inconsistent results, and the effect of the addition of glucose

(Activity expressed as in Table 1. Test organism, B. mycoides.)

\section{Substrate and sample}

Red clover A
B As A. Sept. 1949.
C Broxbourne, hillside. Sept. 1948.
D Brentwood. July 1951.

Red fescue A Writtlenr. Chelmsford. Sept. 1947. Haulms still green.

B Brentwood. Sept. 1949. Haulms still green.

C Brentwood. July 1951. Aberystwyth strain S. 59. Haulms straw coloured after threshing of seeds.

D Aberystwyth. July 1951. Same strain as in C. Aftermath growth after cutting back panicles.

Mustard A Brentwood. July 1948. Haulms still green.

B Brentwood. Sept. 1948. Haulms straw coloured.

Rye grass A Brentwood. July 1948.

B Broxbourne, hillside. July 1948.
Relative antibacterial activity (\%)

\begin{tabular}{|c|c|}
\hline Alone & $\begin{array}{c}\text { With } 3 \cdot 5 \% \\
\text { glucose }\end{array}$ \\
\hline 0 & - \\
\hline 0 & - \\
\hline 62 & 372 \\
\hline 0 & - \\
\hline 0 & 147 \\
\hline 32 & 348 \\
\hline 84 & 400 \\
\hline 108 & 201 \\
\hline 0 & 174 \\
\hline 21 & 300 \\
\hline 0 & - \\
\hline 83 & - \\
\hline
\end{tabular}

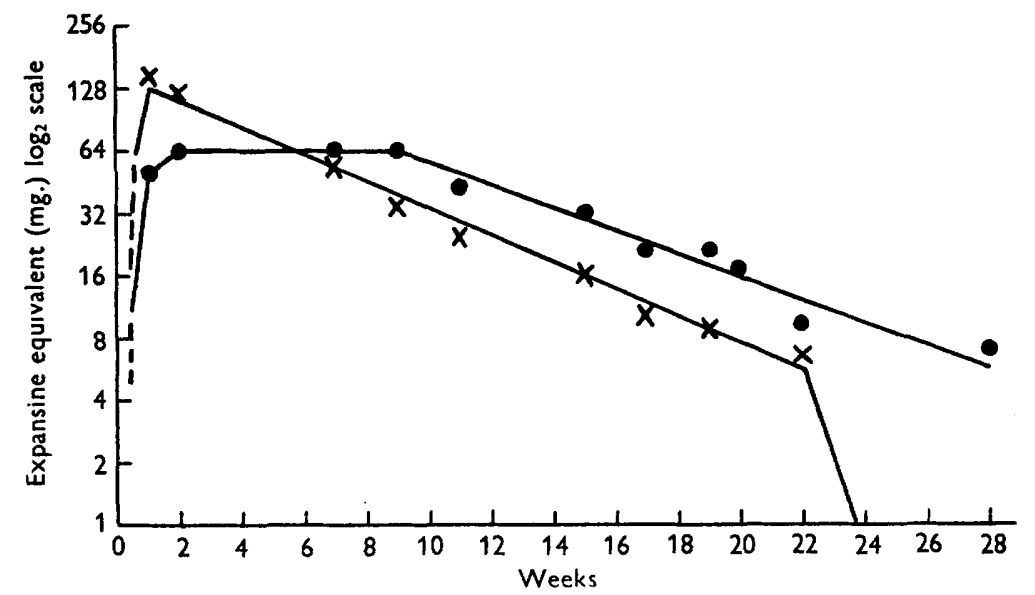

Fig. 1. The antibacterial activity of cultures of Penicillium patulum on wheat straw and timothy grass. $x-x$, timothy grass; 
general picture is similar to that with $\boldsymbol{P}$. patulum; sugar-beet pulp, timothy grass and wheat straw are adequate materials in decreasing order of efficiency.

The fluids obtained from cultures of $A$. terreus on wheat straw and timothy grass were active against $\boldsymbol{B}$. mycoides but inactive against $\boldsymbol{B}$ act. carotovorum, whereas $A$. clavatus cultures on all these materials were nearly equally active against both organisms. It was further observed that the zones of inhibition

Table 3. The antibacterial activity of cultures of Aspergillus clavatus and

A. terreus growing on different substrates

\begin{tabular}{|c|c|c|c|c|}
\hline \multirow[b]{3}{*}{ Substrate } & \multicolumn{4}{|c|}{ Expansine equivalent (mg.) } \\
\hline & \multicolumn{2}{|c|}{ A. clavatus } & \multicolumn{2}{|c|}{ A. terreus } \\
\hline & B. mycoides & $\begin{array}{c}\text { Bact. } \\
\text { carotovorum }\end{array}$ & B. mycoides & $\begin{array}{c}\text { Bact. } \\
\text { carotovorum }\end{array}$ \\
\hline Fresh wheat straw & 28 & 30 & 11 & 0 \\
\hline $\begin{array}{l}\text { Fresh wheat straw }+3.5 \% \\
\text { glucose }\end{array}$ & 110 & 117 & 38 & 6 \\
\hline Sugar-beet pulp & 49 & 50 & 21 & $\mathbf{3}$ \\
\hline Timothy grass & 40 & 41 & 13 & 0 \\
\hline Fescue & $0^{*}$ & $0 *$ & $\mathbf{0}$ & $\mathbf{0}$ \\
\hline Mustard & $0^{*}$ & $0^{*}$ & 0 & 0 \\
\hline Lucerne & $\mathbf{0}$ & $\mathbf{0}$ & 0 & $\mathbf{0}$ \\
\hline Horse manure & 0 & $\mathbf{0}$ & $\mathbf{0}$ & $\mathbf{0}$ \\
\hline
\end{tabular}

* Results were variable: low antibiotic activity was occasionally observed on these substrates.

of $B$. mycoides with the $A$. terreus fluids had ragged edges, whereas this organism gives sharp-edged zones with expansine solutions (Pl. 1, figs. 1, 2). Although $A$. terreus does form expansine (Kent \& Heatley, 1945) the above observations suggest that it is not formed on wheat straw or timothy. However, cultures on wheat straw with added glucose, and on sugar-beet pulp, were both slightly active against Bact. carotovorum and possibly expansine was present therein, suggesting that expansine formation depends even more strongly with $\boldsymbol{A}$. terreus than with $\boldsymbol{A}$. clavatus on the presence of easily available carbohydrate.

Antibiotic formation by Penicillium patulum in autoclaved soil

Grossbard (1947, 1948a) showed that while unsupplemented autoclaved soil did not support antibiotic production by $\boldsymbol{P}$. patulum, the addition of energy-yielding materials led to a positive response. Therefore the ability of sugar-beet pulp and wheat straw to support antibiotic production by $\boldsymbol{P}$. patulum when incorporated in soil at various concentrations and the mixtures autoclaved, was compared with that of soil + glucose. In addition, comparisons were made between completely untreated soil, autoclaved but unsupplemented and uninoculated soil, and autoclaved unsupplemented but inoculated soil. Assays were made after 14 days, against both $B$. mycoides and Bact. carotovorum.

Evidently, for antibiotic production to occur the substrate must be autoclaved and inoculated with the fungus (PI. 1, figs. 2, 3, $e, h, i)$. No anti- 
biotic was produced unless these conditions were fulfilled $(b, c, d, f, g)$. However, $\boldsymbol{B}$. mycoides was stimulated by materials in the centrifugate from untreated soil, and this effect was increased when the soil was autoclaved (Pl. 1, fig. 2, b, c). There was no further response when non-supplemented autoclaved soil was inoculated (PI. 1, fig. 2, $d$ ). When the soil was supplemented with sugar-beet pulp but not autoclaved a slight lytic effect, as yet unexplained, was observed (P1. 1, fig. 2, $f$ ). This disappeared on autoclaving, but the zone

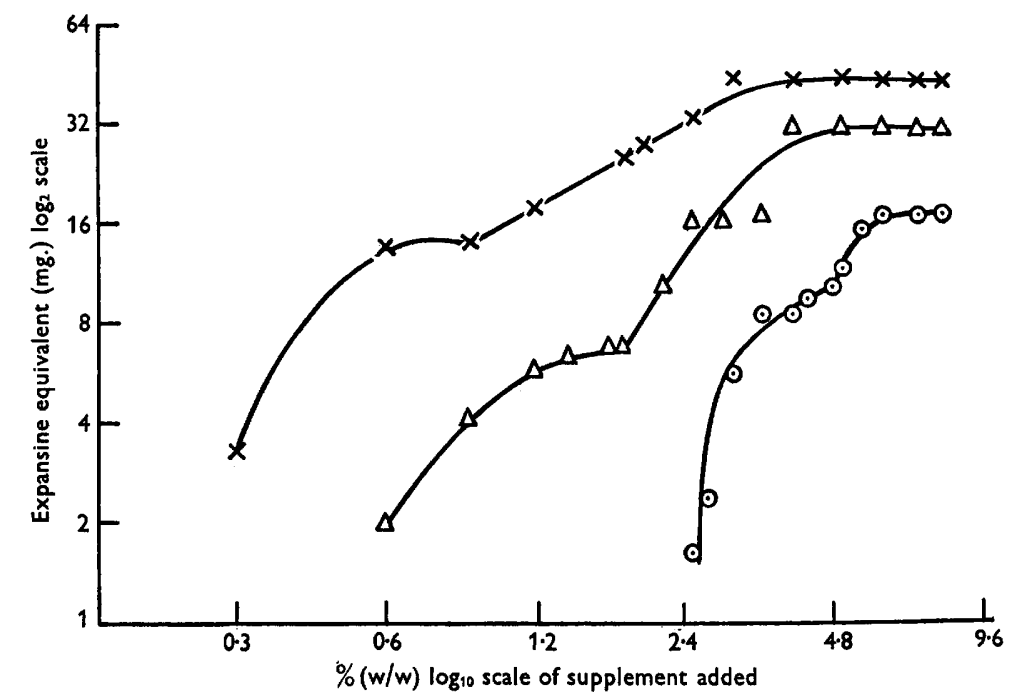

Fig. 2. Antibacterial activity of centrifugates from autoclaved soil receiving various supplements and inoculated with $P$. patulum. $\times-\times$, glucose; $\triangle-\triangle$, sugar-beet pulp; $\odot-\odot$, wheat straw. Test organism, $B$. mycoides.

of stimulation was larger (Pl. 1, fig. 2, g). Bact. carotovorum was not stimulated by the unsupplemented soil centrifugates which stimulated $B$. mycoides, as shown in Pl. 1, fig. 3, $b-d$, but there was some stimulation with sugar-beet pulp (Pl. 1, fig. 3, $f, g$ ).

As shown by Grossbard (1948b) centrifugates from certain untreated soils did occasionally give narrow zones of partial inhibition not only of Bact. coli but also of Bact. carotovorum. In the present work, very large zones of weak partial inhibition of Bact. carotovorum were obtained with centrifugates from glucose supplemented but uninoculated soils; occasionally this effect was observed even with $B$. mycoides.

The quantitative data of this experiment are given in Fig. 2. The expansine equivalents have been plotted against the amount of material added (logarithmic scales in both cases), and it can be seen that weight for weight glucose was more effective than sugar-beet pulp, wheat straw being still less valuable, although effective when in sufficient amount. Three features of the curves are striking. First, there was a threshold quantity necessary for appreciable antibiotic formation with each material, the amounts varying from $\mathbf{0 . 3} \%$ with glucose to $2.5 \%$ with wheat straw. Secondly, maximum production, which 
reached different levels in the three cases, was attained over a much narrower range, the order being the same as with the threshold quantities. Thirdly, each of the graphs relating $\log _{10}$ concentration to $\log _{2}$ expansine equivalent shows a 'two-stage' effect; apparently a first maximum in production was reached with a relatively small amount of each material, with subsequent further stimulation of activity when larger amounts were added. The reason for this is at present obscure. It may be an artefact due to the cycle of increase and decrease in antibiotic (Fig. 1) having differed in duration with the different rates of addition of each supplement. If the effect is real, it might be ascribed to the production of two antibiotics at different rates and with different threshold levels and maxima, so that in reality two antibiotic production curves are superimposed.

Table 4. The antifungal activity of centrifugates taken from autoclaved soils receiving 2.5 or $5 \%$ (w/w) of various supplements, and compared with their antibacterial activity

\begin{tabular}{|c|c|c|c|c|c|c|}
\hline \multirow[b]{3}{*}{ Centrifugates from } & \multicolumn{2}{|c|}{ pHI value } & & & & \\
\hline & \multirow{2}{*}{$\begin{array}{c}\text { Before } \\
\text { incubation } \\
\text { with } \\
P . \text { patulum }\end{array}$} & \multirow{2}{*}{$\begin{array}{c}\text { After } \\
\text { incubation } \\
\text { with } \\
P . \text { patulum }\end{array}$} & \multicolumn{4}{|c|}{ Highest dilution giving complete inhibition of } \\
\hline & & & Ph. parasitica* & T. basicola* & B. mycoides $\dagger$ & $\begin{array}{c}\text { Bact. } \\
\text { carotovorum }\end{array}$ \\
\hline Soil only & $5 \cdot 25$ & $5 \cdot 89$ & Stimulation & Stimulation & Stimulation & No activity \\
\hline $\begin{array}{cc}\text { Soil + glucose } & 2 \cdot 5 \% \\
", \quad & \mathbf{5} \cdot 0 \%\end{array}$ & $\begin{array}{l}5 \cdot 63 \\
5 \cdot 23\end{array}$ & $\begin{array}{l}4 \cdot 93 \\
4 \cdot 55\end{array}$ & $\begin{array}{l}1 / 100 \\
1 / 100\end{array}$ & $\begin{array}{l}1 / 100 \\
1 / 100\end{array}$ & $\begin{array}{l}1 / 40 \\
1 / 40\end{array}$ & $\begin{array}{l}1 / 40 \\
1 / 40\end{array}$ \\
\hline $\begin{array}{c}\text { Soil + sugar-beet pulp } 2.5 \% \\
" \quad, \quad " \quad, \quad 5.0 \%\end{array}$ & $\begin{array}{l}4 \cdot 77 \\
4 \cdot 96\end{array}$ & $\begin{array}{l}4 \cdot 94 \\
4 \cdot 84\end{array}$ & $\begin{array}{l}1 / 80 \\
1 / 100\end{array}$ & $\begin{array}{l}1 / 40 \\
1 / 80\end{array}$ & $\begin{array}{l}1 / 30 \\
1 / 40\end{array}$ & $\begin{array}{l}1 / 30 \\
1 / 40\end{array}$ \\
\hline $\begin{array}{cc}\text { Soil + wheat straw } & 2.5 \% \\
, \quad, \quad, \quad 5.0 \%\end{array}$ & $\begin{array}{l}5 \cdot 03 \\
5 \cdot 02\end{array}$ & $\begin{array}{l}4 \cdot 86 \\
5 \cdot 25\end{array}$ & $\begin{array}{l}1 / 10 \\
1 / 20\end{array}$ & $\begin{array}{l}1 / 5 \\
1 / 10\end{array}$ & $-\overline{1}$ & $\begin{array}{l}1 / 5 \\
1 / 20\end{array}$ \\
\hline
\end{tabular}

The fluids obtained from these supplemented soils, autoclaved and inoculated with $\boldsymbol{P}$. patulum, also possessed considerable antifungal activity as shown in Table 4, which gives the dilutions of the soil centrifugates at which complete inhibition of $\boldsymbol{P h}$. parasitica and $\boldsymbol{T}$. basicola occurred, the soils having received additions of $2 \cdot 5$ or $5 \%$ of glucose, sugar-beet pulp or wheat straw. Glucose was the most potent substance, followed closely by sugar-beet pulp, with wheat straw much less effective. Table 4 also shows the dilutions at which the centrifugates were inhibitory for B. mycoides and Bact. carotovorum. The antifungal activity was higher than the antibacterial. Expansine shows this type of activity.

Antibiotic production by various fungi in autoclaved supplemented soils

The property of forming an antibiotic in autoclaved supplemented soils is not restricted to $P$. patulum. In Fig. $3 \boldsymbol{P}$. patulum has been used as a standard for assessing the activities of $A$. clavatus, $A$. terreus and two unidentified 
species of Penicillium in soils supplemented with glucose, sugar-beet pulp or wheat straw.

The pattern of relative activities varied with the different substrates and test organisms used, but $A$. clavatus and Penicillium species A were about equally efficient and slightly less active than $P$. patulum; next came $A$. terreus; least active was $\boldsymbol{P e n i c i l l i u m}$ species $\mathbf{B}$ which was inactive against $\boldsymbol{B}$. mycoides on soil + straw and against Bact. carotovorum on all substrates. In soil supplemented with wheat straw or sugar-beet pulp, $A$. terreus failed to yield an
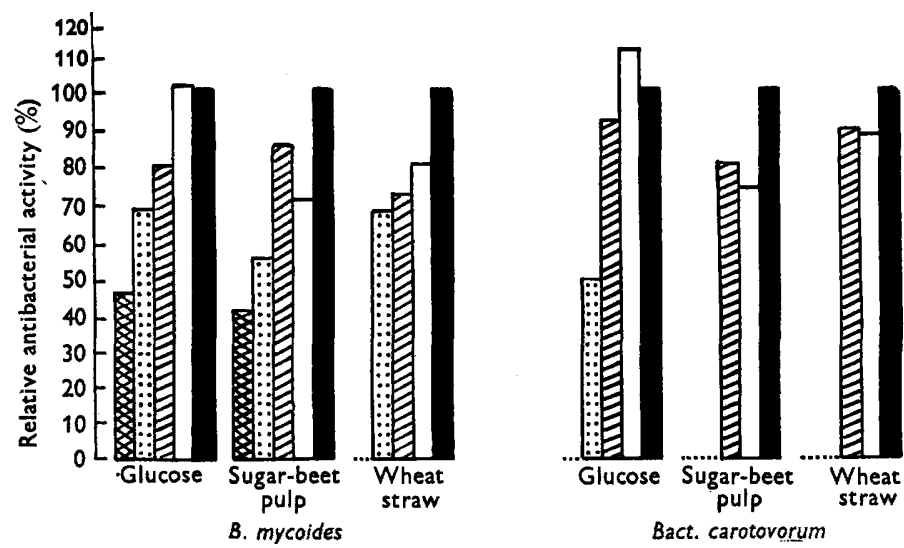

Fig. 3. The relative antibacterial activity of centrifugates from autoclaved soils receiving various supplements and inoculated with five different fungi. $\square$, Penicillium sp. A; \&, Penicillium sp. B; $\square$, Aspergillus clavatus; ⿷., A. terreus;, P. patulum.

antibiotic completely inhibiting the growth of Bact. carotovorum, though in the latter case good partial inhibition of that organism was obtained. Fig. 3 does not, however, include partial inhibitions. In experiments not involving soil, which were not intended as true comparisons, $A$. clavatus proved only a little more than half as active as $\boldsymbol{P}$. patulum (Table 3 ). However, in the present experiment a different isolate was used.

\section{Antibiotic production by Penicillium patulum in soil containing other micro-organisms}

The work described above shows that various fungi can form considerable quantities of antibiotics when grown in pure culture in supplemented and autoclaved soil. The results cannot, however, be directly related to practical conditions for the reason that the soil and the supplements were both subjected to autoclaving, which eliminates the normal flora and may have broken down the organic matter of the soil and of the supplements, causing possibly an enhanced availability of nutrients. In glasshouse practice steaming is used and moderate release of nutrients could occur from both the soil and the supplements, while part of the microflora of the soil would remain to multiply and compete with the antibiotic producer. In the field full competition by the soil flora would occur and there would be no comparable release of nutrients, except by microbial action. Experiments were therefore carried out to study 
antibiotic production in non-sterile supplemented soil and in steamed supplemented soil, both inoculated with $\boldsymbol{P}$. patulum. The supplements were 2.5 or $4.0 \%$ of sugar-beet pulp or wheat straw, with glucose as a standard.

In no case was any antibiotic detected in the non-sterilized supplemented soils. In Table $\mathbf{5}$ a comparison is given between the results for steamed and autoclaved soil, similarly supplemented.

Table 5. A comparison of the antibacterial activity of centrifugates from supplemented steamed or autoclaved soils, prepared 14 days after inoculation with Penicillium patulum

The soil used was different from that used in previous experiments: it was a light loam top soil with a large quantity of plant residue.

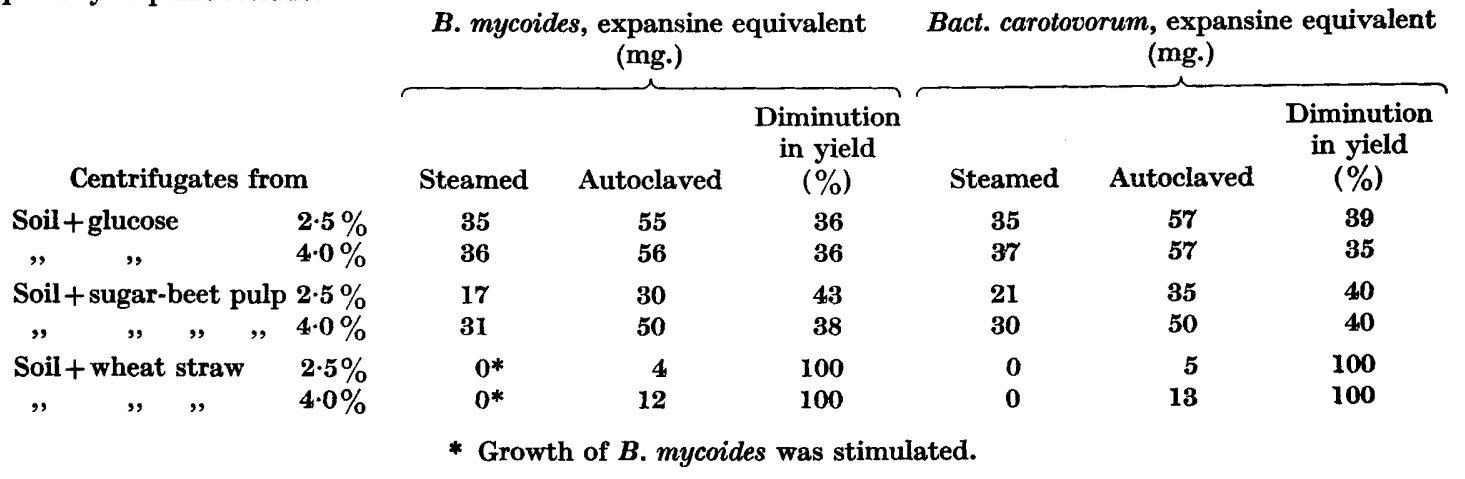

The steamed mixtures of soil and sugar-beet pulp or glucose supported antibiotic production by $\boldsymbol{P}$. patulum, but activity was lower than when they were autoclaved. This may have been due to competition by the surviving microflora or to lower concentrations of nutrients released by steaming as compared with autoclaving. It is clear, however, that competition from soil organisms which survive the steaming process was not effective in suppressing antibiotic formation in the soil to any great extent, except in the soil-straw mixtures, which were wholly inactive.

\section{Persistence of antibiotic after contamination of cultures on autoclaved soil}

Waksman (1950) stated that even if antibiotics were formed in the soil they would not persist owing to destruction by other micro-organisms. However, Nandi (1948), Sinha (1950), Nimkar (1950) and M. Monib (private communication) showed that certain purified antibiotics when added to non-sterile soil did persist for varying periods during which they exerted an influence on the soil microflora. Jefferys (1950) and Gottlieb \& Siminoff (1950 a) also found evidence of antibiotic persistence in soil. These authors used expansine in addition to several other antibiotics.

In order to study the effect of a freshly introduced microflora on the titre of an antibiotic in soil, Erlenmeyer flask cultures of $\boldsymbol{P}$. patulum on autoclaved soil $+2.5 \%$ of glucose and in which the antibiotic had already been formed, were inoculated (contaminated) with other micro-organisms. This inoculation 
was effected either by adding $20 \%$ of non-sterilized soil of the same type and mixing it with the cultures in the flasks and re-plugging, or by transferring soil from the flasks into open jam jars. The latter were placed under bell jars in which the atmosphere was saturated with water vapour to eliminate evaporation. Each of the two sets was divided into two lots, one being kept at room temperature (mean value $15^{\circ}$ ) and the other in an incubator at $25^{\circ}$. Another set of flasks, not contaminated, served as a control and was kept in an incubator at $25^{\circ}$. The various activities are recorded in Table 6.

\section{Table 6. Relative antibacterial activities of sterilized soil containing antibiotic and the same subsequently contaminated with other organisms}

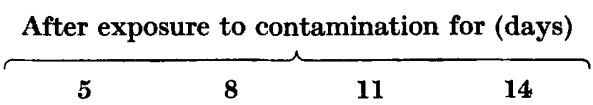

$\quad$ Source of
contamination
None
Air
Non-sterile soil
Air
Non-sterile soil

\begin{tabular}{crrrr} 
& \multicolumn{4}{c}{ Relative activity (\%)* } \\
Temp. & $\overbrace{25}$ & & & \\
$25^{\circ}$ & 100 & 85 & 74 & 13 \\
$15^{\circ} \dagger$ & 92 & 55 & 85 & 62 \\
$15^{\circ} \dagger$ & 42 & 33 & 20 & 2 \\
$25^{\circ}$ & 37 & 12 & 29 & 0 \\
$25^{\circ}$ & 30 & 25 & 0 & 0
\end{tabular}

* Expressed as a percentage of the expansine equivalent at the start, which was $60 \mathrm{mg}$. by $\boldsymbol{B}$. mycoides assay.

$\dagger$ Mean value during the experiment.

After 5 days the control still showed the initial activity, but subsequently there was a slow fall, and after 14 days comparatively little activity was left. Cultures exposed to the air and left at room temperature behaved differently, the activity declining a little after 5 days, but markedly in the next 3 days and then increasing again to a high level, followed by a slow decline. At 14 days, activity was higher than in the not contaminated cultures. However, no great significance should be attached to this because in previous experiments activity was lost on exposure to air at the same time as in the controls. Exposure at $25^{\circ}$ led to a similar pattern of changes but at a lower level as the decline after 5 days was greater, and the antibiotic content fell to zero after 14 days' exposure. Contamination with soil, whether at room temperature or at $25^{\circ}$, caused a large decrease in activity in 5 days; subsequently there was a further slow decline in each case. At $25^{\circ}$ no activity was detected after 11 days, but at room temperature the decline was slower and some activity was still present even after 14 days. The irregularity of the fluctuations makes interpretation of the results difficult. However, it is clear that even gross contamination with soil did not lead to immediate destruction of all antibiotic activity. Temperature appeared to have some effect, as at $25^{\circ}$ the decreases in activity were larger and more rapid. 


\section{DISCUSSION}

The fungi $P$. patulum, $A$. clavatus and $A$. terreus can produce antibiotic material on various organic manures but fail to do so on others. Suitable materials, when composted, became unsuitable as substrates for $\boldsymbol{P}$. patulum for antibiotic production. However, the addition of glucose to composted manures and to materials inadequate even in the fresh state rendered them suitable, and it also increased the titre of cultures of all fungi on adequate manures. These results suggest that available carbohydrate is the prime requirement for antibiotic production on these substrates. Soil itself, at least after autoclaving or steaming, contains all the nutrients required for antibiotic production by the fungi tested except energy-providing materials, as shown by the production of antibiotics in such soils after addition of glucose.

Whether unheated soil also contains sufficient nutrients apart from energy sources cannot be stated at present. The failure to obtain antibiotic production in non-sterile soil supplemented in various ways may have been due to lack of nutrients, to competition by the soil flora, or to failure to detect the low concentrations of antibiotic to be expected in a natural soil. To decide the first point, experiments on sterilization of the soil by a method which should not lead to the release of nutrients are now in progress, namely by the use of propylene oxide. Preliminary results have shown that antibiotic formation takes place in glucose supplemented soil, treated with propylene oxide, but with lower yields than in heated soil. From this, one may conclude that soil may be adequate for antibiotic production, provided an energy source is supplied in addition.

Competition by the soil microflora may be an important factor in the limitation of antibiotic production by suppressing the growth of the antibioticproducing organism or by inhibiting antibiotic production. However, not every type of microbial competition can entirely prevent antibiotic production. This is shown by the experiments with steamed soil + glucose and steamed soil + sugar-beet pulp mixtures. Although part of the original microflora must have survived, at least in the form of spores, antibiotic production took place, though with lower yields. No antibiotic was formed in the steamed soil + straw mixture. Steamed straw, without soil, was an unsatisfactory substrate, antibiotic production being very irregular. Sufficient nutrients may not have been available, and possibly the surviving flora was somewhat different from that on sugar-beet pulp. These suggestions receive support from the results of preliminary work with propylene oxide. While sugar-beet pulp is easily sterilized by this substance and the titre of antibiotic formed by $\boldsymbol{P}$. patulum is almost as great as on autoclaved sugar-beet pulp, it is difficult to achieve complete sterility of wheat straw with propylene oxide. The cultures frequently failed to yield antibiotic, or only low yields were obtained. However, when glucose was added to straw treated with propylene oxide, antibiotic of high concentration was formed readily.

The microflora might also act by gradually destroying antibiotic. This conclusion is in line with the results of the contamination experiment and 
with the report of Krebs (1944) on the existence of an enzyme which hydrolyses expansine. However, Jefferys (1950) and Gottlieb \& Siminoff (1950b) showed that expansine persists for a considerable time when added to nonsterile soil. It is possible, therefore, that in non-sterile soil local concentrations of antibiotic occur in the vicinity of energy-yielding particles, as suggested by Brian et al. (1951), and that organic manuring, by increasing the content of energy-yielding matter, induces antibiotic production.

In this connexion it is significant that a parallel exists between the requirements essential for antibiotic production by the fungi tested and the conditions necessary for the control of certain root diseases. The fact that some plant materials were suitable, while others, e.g. certain samples of red clover or rye grass were unsuitable, for antibiotic production, fits the results of West \& Hildebrand (1941) and of Rouatt \& Atkinson (1950), that while soybeans were effective, red clover and rye grass were ineffective in controlling certain plant diseases. Further, abundant carbohydrate must be present if an antibiotic is to be produced by the tested fungi. This can be correlated with the finding of Nandi (1948) who succeeded in extracting from non-sterile soil reinforced with glucose material which showed marked antibacterial properties, and with the evidence in the literature (Garrett, 1938; West \& Hildebrand, 1941; Blair, 1943; Grossbard, 1946, 1949; Rouatt \& Atkinson, 1950) that soil supplements high in carbohydrate are effective in the control of some root diseases. These effective materials are also low in nitrogen, and work to be published later suggests that increase of nitrogen concentration decreases antibiotic production by $\boldsymbol{P}$. patulum in soil. Thus the results showing the controlling effect of carbohydrate manuring on certain soil-borne diseases should not be entirely dissociated from the possibility that this treatment resulted not only in a modification of the composition of the microflora but also in a formation of local concentrations of antibiotics, perhaps only temporary, which may have exerted an inhibitory action on plant pathogens in the neighbourhood of the roots of host plants.

As authority for the names of plant materials, L. H. Bailey's Manual of Cultivated Plants, (1949) and for the bacteria W. J. Dowson's Manual of Bacterial Plant Diseases (1949) have been used.

I wish to thank the Agricultural Research Council for a grant which enabled this work to be carried out. A large proportion of the work was done at the Experimental and Research Station, Cheshunt, under the guidance and advice of Dr W. F. Bewley, to whom I am greatly indebted. I wish to thank Dr S. E. Jacobs for his guidance, valuable suggestions and for his help in preparing this paper. Technical assistance, by Mrs D. Sapsford, Miss M. Beadon, Miss C. Liss and Mr H. Tooley who prepared the photographs, is gratefully acknowledged.

\section{REFERENCES}

Bailey, L. H. (1949). Manual of Cultivated Plants. New York: Macmillan.

Brarr, I. D. (1943). Behaviour of the fungus Rhizoctonia solani Kühn in the soil. Ann. appl. Biol. 30, 118.

Brian, P. W., Wright, J. M., Stubbs, J. \& WAy, A. M. (1951). Uptake of antibiotic metabolites of soil micro-organisms by plants. Nature, Lond. 167, 347. 
Dowson, W. J. (1949). Manual of Bacterial Plant Diseases. London: A. and C. Black.

Garretr, S. D. (1938). Soil conditions and the take-all disease of wheat. Ann. appl. Biol. 25, 742.

GarreTt, S. D. (1944). Root Disease Fungi. Waltham, Mass., U.S.A.: Chronica Botanica Company.

Gottlieb, D. \& Siminoff, P. $(1950 a)$. The role of antibiotics in the soil. Abstr. Phytopathology, 40, 11.

Gottlieb, D. \& Siminoff, P. (1950b). The activity of antibiotics in soil. Proc. seventh int. Bot. Congr. (in the Press).

Grossbard, E. (1945). Control of plant diseases by microbial antagonism. Rep. exp. Res. Sta. Cheshunt, 31, 55.

Grossbard, E. (1946). The control of plant diseases by microbial antagonism. Rep. exp. Res. Sta. Cheshunt, 32, 41.

Grossbard, E. (1947). The control of plant diseases by microbial antagonism. Rep. exp. Res. Sta. Cheshunt, 33, 29.

Grossbard, E. (1948 a). Production of an antibiotic substance on wheat straw and other organic materials and in the soil. Nature, Lond. 161, 614.

Grossbard, E. $(\mathbf{1 9 4 8} b)$. Investigations on microbial antagonism and antibiotic substances. Rep. exp. Res. Sta. Cheshunt, 34, 37.

Grossbard, E. (1949). Investigations on microbial antagonism and antibiotic substances. Rep. exp. Res. Sta. Cheshunt, 35, 38.

Grossbard, E. (1950). The production of antibiotics in the soil. Proc. seventh int. Bot. Congr. (in the Press).

Jefferys, E. G. (1950). Antibiotics in soil ecology. Proc. seventh int. Bot. Congr. (in the Press).

Kent, J. \& Heatley, N. G. (1945). Antibiotics from moulds. Nature, Lond. 156, 295.

KreBs, H. A. (1944), Enzymic hydrolysis of patulin. Biochem. J. 38, xxxix.

Leonian, L. H. (1934). The identification of Phytophthora species. Bull. W. Va agric. Exp. Sta. no. 262.

Lewis, I. M. (1929). Bacterial antagonism with special reference to the effect of Pseudomonas fluorescens on spore forming bacteria of soils. J. Bact. 17, 89 .

NANDI, P. N. (1948). The influence of antibiotics on micro-organisms in soil. Ph.D. Thesis, University of London.

Nickell, L. G. \& Burkmolder, P. R. (1947). Inhibition of Azotobacter by soil actinomycetes. J. Amer. Soc. Agron. 39, 771.

NimkaR, S. (1950). The response of the soil microflora to treatment with certain antibiotics. Ph.D. Thesis, University of London.

Raper, K. B. \& Thom, C. (1949). A Manual of the Penicillia. Baltimore: Williams and Wilkins.

Rouat,, J. W. \& Atrinson, R. G. (1950). The effect of the incorporation of certain cover crops on the microbiological balance of potato scab infested soil. Canad. J. Res. C, 28, 140.

Sinha, P. (1950). Antibiotics in relation to the micro-organisms of the soil. Ph.D. Thesis, University of London.

Waksman, S. A. (1948). Antibiotics. Biol. Rev. 23, 452.

Waksman, S. A. (1950). Antibiotics and their significance in the physiology of micro-organisms. Proc. seventh int. Bot. Congr. (in the Press).

Waksman, S. A. \& WoodrufF, H. B. (1942). The occurrence of bacteriostatic and bacteriocidal substances in the soil. Soil. Sci. 53, 233.

West, P. M. \& Hrldebrand, A. A. (1941). The microbiological balance of strawberry root rot soil as related to the rhizosphere and decomposition effects of certain cover crops. Canad. J. Res. C, 19, 199.

Winter, A. G. (1940). Untersuchungen über den Einfluss biotischer Faktoren auf die Infektion des Weizen durch Ophiobolus graminis. Z. PflKrankh. 50, 113. 


\section{EXPLANATION OF PLATE}

\section{(Magnification $\times \frac{2}{3}$ )}

Fig. 1. Assay of the culture fluid of $A$. terreus growing on wheat straw, using B. mycoides. Note diffused edges of the zones with the rhizoid outgrowths of the colonies protruding into the area of inhibition: this picture does not alter, the areas of inhibition do not become overgrown.

Fig. 2. Assay of centrifugates from a soil receiving various treatments. Test organism: B. mycoides. a, expansine in a buffer solution, 1 g./. $b$, completely untreated. Note stimulation. $c$, not supplemented, not inoculated, but autoclaved. Note increase in zone of stimulation. $d$, not supplemented, but autoclaved and inoculated with $P$. patulum. Centrifugate prepared 14 days after incubation at $25^{\circ}$. e, supplemented with glucose and inoculated as in $d . f$, supplemented with sugar-beet pulp but not autoclaved or inoculated. $g$, as $f$ but autoclaved. Note increase in zone of stimulation. $h$, as $g$ but inoculated with $P$. patulum. Note distinct wide zone of stimulation following the zone of inhibition. $i$, as $h$ but supplemented with wheat straw.

Fig. 3. As fig. 2, but the test organism is Bact. carotovorum. Zones of stimulation are generally slight or absent. Arrangement of centrifugates as in fig. 2.

(Received 27 September 1951) 
Journal of General Microbiology, Vol. 6, Nos. 3 and 4

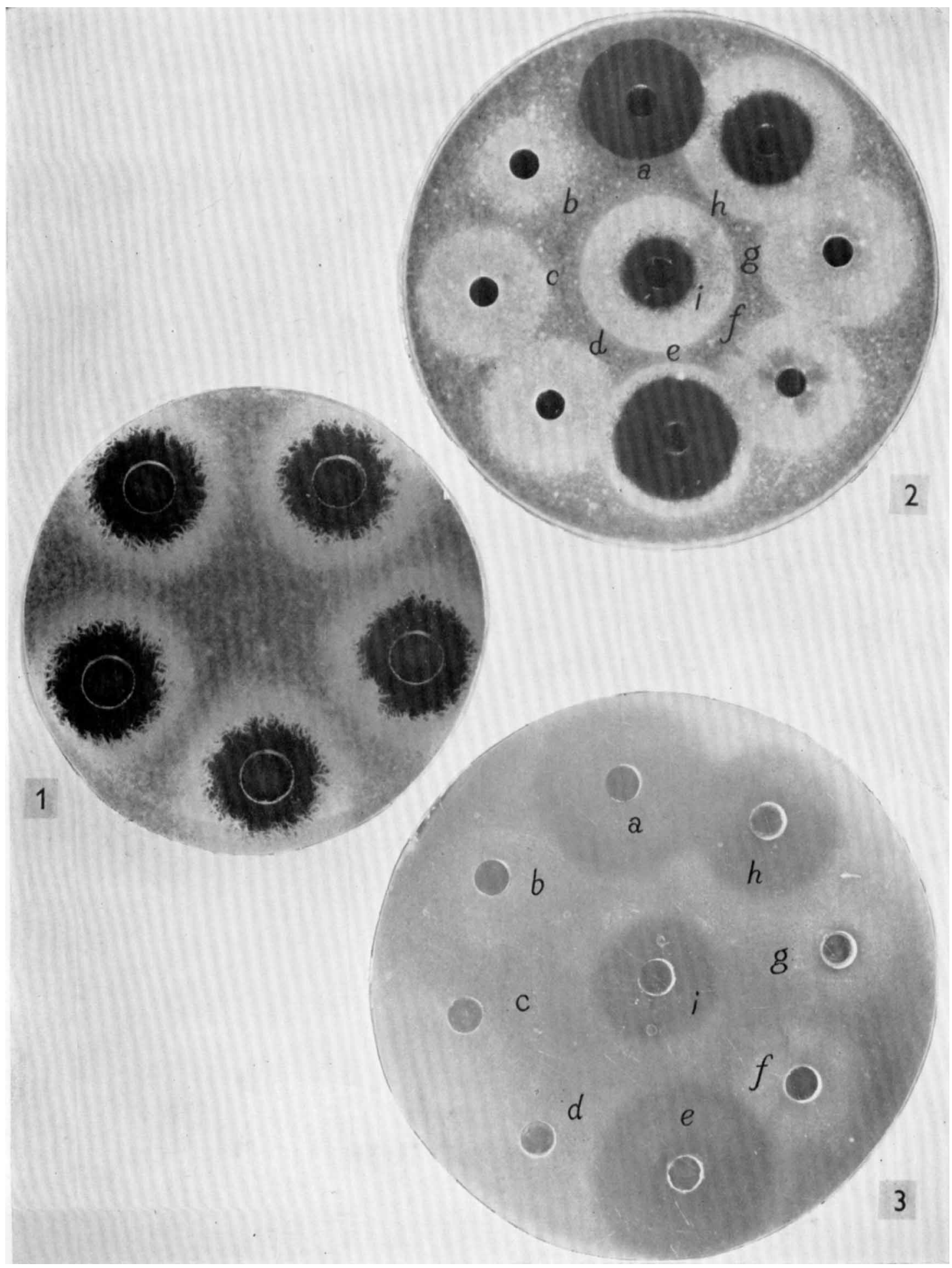

E. Grossbard-Antibiotic production by fungi in soll. Plate 1 